Research Article

\title{
Structural Redundancy Assessment of Adjacent Precast Concrete Box-Beam Bridges in Service
}

\author{
Yanling Leng $\left(\mathbb{D},{ }^{1}\right.$ Jinquan Zhang, ${ }^{2}$ Ruinian Jiang $\mathbb{D},{ }^{3}$ and Yangjian Xiao ${ }^{2}$ \\ ${ }^{1}$ Senior Bridge Engineer, Clark Engineering Corp., Huron, USA \\ ${ }^{2}$ Chongqing Jiaotong University, Chongqing, China \\ ${ }^{3}$ New Mexico State University, Las Cruces, USA \\ Correspondence should be addressed to Ruinian Jiang; rjiang@nmsu.edu
}

Received 12 September 2019; Revised 18 November 2019; Accepted 8 January 2020; Published 15 February 2020

Guest Editor: Roozbeh Rezakhani

Copyright ( $\odot 2020$ Yanling Leng et al. This is an open access article distributed under the Creative Commons Attribution License, which permits unrestricted use, distribution, and reproduction in any medium, provided the original work is properly cited.

Present approaches for assessing bridge redundancy are mainly based on nonlinear finite element (FE) analysis. Unfortunately, the real behavior of bridges in the nonlinear range is difficult to evaluate and a sound basis for the nonlinear FE analysis is not available. In addition, a nonlinear FE analysis is not feasible for practitioners to use. To tackle this problem, a new simplified approach based on linear FE analysis and field load testing is introduced in this paper to address the particular structural feature and topology of adjacent precast concrete box-beam bridges for the assessment of structural redundancy. The approach was first experimentally analyzed on a model bridge and then validated by a case study. The approach agrees well with the existing recognized method while reducing the computation complexity and improving the reliability. The analysis reveals that the level of redundancy of the bridge in the case study does not meet the recommended standard, indicating that the system factor recommended by the current bridge evaluation code for this bridge is inappropriate if considering the field condition. Further research on the redundancy level of this type of bridges is consequently recommended.

\section{Introduction}

Adjacent precast concrete box-beam bridges have been a popular solution for small and medium span bridges worldwide. The bridges are built by placing precast concrete box-beams side-by-side in parallel, which are then connected laterally by shear keys (hinge joints) longitudinally grouted in between the beams and covered with a concrete deck. The shear keys and the concrete deck provide the transverse connection between the concrete box beams. Tie rods or transverse posttensioning strands are sometimes used to further strengthen the transverse connection.

The system performance of adjacent precast concrete box-beam bridges is presently reflected by the design lateral load distribution factors (LLDFs), which are determined based on the assumption that the points of contact in two adjacent beams deform equally [1]. This assumption does not reflect the actual joint condition between adjacent beams when there are cracks in the joints. In the present design practice, shear keys are relatively weaker compared to the beams and cracking and deterioration of shear keys are prevalent [2]. The prior experimental investigations conducted by the authors revealed that the cracking of shear keys significantly change their functional capability, which causes the load redistribution among beams [3, 4]. Analyses on catastrophic collapse of some adjacent precast concrete box-beam bridges also indicated the fact that the shear keys between the adjacent beams were insufficiently designed [5]. Thus, the redundancy level of adjacent precast concrete boxbeam bridges in service should be evaluated according to the actual conditions of the shear keys and box beams, and the current safety evaluation procedure for this type of bridges should be revisited.

Redundancy is defined as the ability of a bridge to continue to safely carry some level of load in a damaged state [6]. Some bridge codes have considered structural redundancy of bridges in the design and evaluation procedures. For example, redundancy factors have been adopted in the 
LRFD Highway Bridge Design Specification by the American Association of State Highway and Transportation Officials [6], and system factors have been defined in the AASHTO Manual of Bridge Evaluation [7]. However, the determination of redundancy factors or system factors mainly relies on engineering judgment due to lack of practical guidance. The main difficulty in the computation of bridge redundancy lies in the estimation of the ultimate loading capacity of the bridge, which is presently evaluated through a nonlinear finite element (FE) analysis. Normally, pushdown analysis is used to facilitate a complete analysis of collapse sequences in structures. The loading will be increased in a stepwise iterative manner with successive elements reaching their mean capacities till the structure fails or collapses.

On the basis of this principle, Ghosn and his colleagues $[8,9]$ developed a framework to quantify redundancy and robustness for highway bridges. The redundancy ratios $R_{u}$, $R_{f}$, and $R_{d}$ are defined, respectively, as the ratios of (1) the force causing the failure of the system $\left(L F_{u}\right),(2)$ the force causing a considerable deflection of a main member, and (3) the force causing the failure of a damaged bridge system, to the force causing the failure of any member $\left(L F_{1}\right)$. A bridge system is considered redundant if the redundancy ratios, computed according to equations (1) through (3), satisfy the following conditions: $R_{u} \geq 1.30 ; R_{f} \geq 1.10$; and $R_{d} \geq 0.50$.

$$
\begin{aligned}
& R_{u}=\frac{L F_{u}}{L F_{1}}, \\
& R_{f}=\frac{L F_{f}}{L F_{1}}, \\
& R_{d}=\frac{L F_{d}}{L F_{1}} .
\end{aligned}
$$

This methodology has been generally recognized; however, it is impractical for practitioners to conduct a nonlinear FE analysis; in addition, the nonlinear FE analysis results cannot be verified without the knowledge of the bridge behavior in the nonlinear range. Field load testing, including diagnostic load testing and proof load testing, can only capture the linear response of in-service bridges at specific load levels. As shown in Figure 1, the diagnostic test load defined in a diagnostic test and the target proof load specified in a proof load test are both smaller than the elastic load limit of the bridge; nonlinear behavior is not tested because of the safety considerations.

This paper summarizes the test results on a model adjacent precast concrete box-beam bridge. A parameter sensitivity study was performed to identify factors that have most influence on the loading capacity of the bridge system. It was found that the three most sensitive parameters are all associated with the properties of shear keys, indicating that the behavior of shear keys plays a dominant role in the performance of adjacent precast concrete box-beam bridges. A method is proposed accordingly based on a linear FE analysis and field deflection measurement, which is able to address the particular structural feature and topology of adjacent precast concrete box-beam bridges. The method

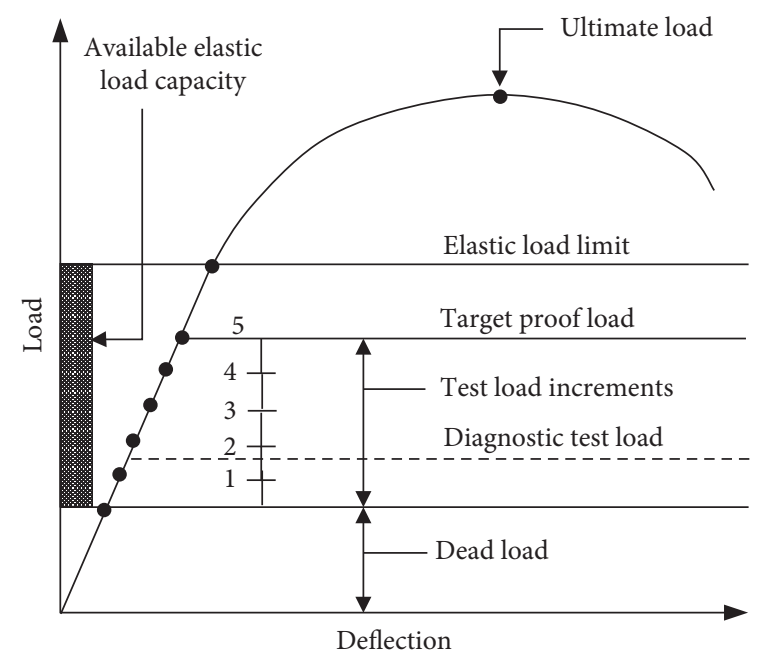

FIgURE 1: Hypothetical load-deflection response of a bridge [10].

was analyzed theoretically based on the experiment results and validated by a case study on a bridge in service. The results obtained with the new approach agree well with those obtained by using the recognized method proposed by Ghosn and his colleagues. The computing complexity is reduced in the proposed method, which makes it suitable for the practitioners to use. It is verified that the level of redundancy of the bridge in the case study does not meet the recommended code standard.

\section{Experimental Investigation on Lateral Load Distribution among Beams}

A model adjacent precast reinforced concrete box-beam bridge was tested in the full load range.

The model bridge used China's standard drawing of a 10meter prefabricated prestressed concrete hollow core slab beam as a prototype [11], which consists of eight slab beams, each 1-meter wide. The scale of the model bridge is $1: 2$, that is, the span was reduced to five meters. The shape and sizes of the cross section of the test beams and joints were determined so that the moment and shear stresses remained unchanged from the original beams. A comparison of the cross sections of the original and model beams is presented in Figure 2. As principal transverse connectors, shear keys play a critical role in the integrity of the bridge. The pavement is composed of a concrete deck and a wearing course on top of it. The deck also helps distribute loads transversely. Both the prototype and model bridges used shallow shear keys without transverse prestressing rods, which were the prevalent precast adjacent box-beam bridges built in or before the 1990s. These bridges were built according to the old design standards and construction techniques, which are lower than their counterparts employed nowadays; as a result, these bridges are more vulnerable and have a higher demand for safety evaluation. In addition, visual inspection of grouted shallow shear keys is difficult while the bridges are in service because of the compact shallow shear key configuration; the poor 


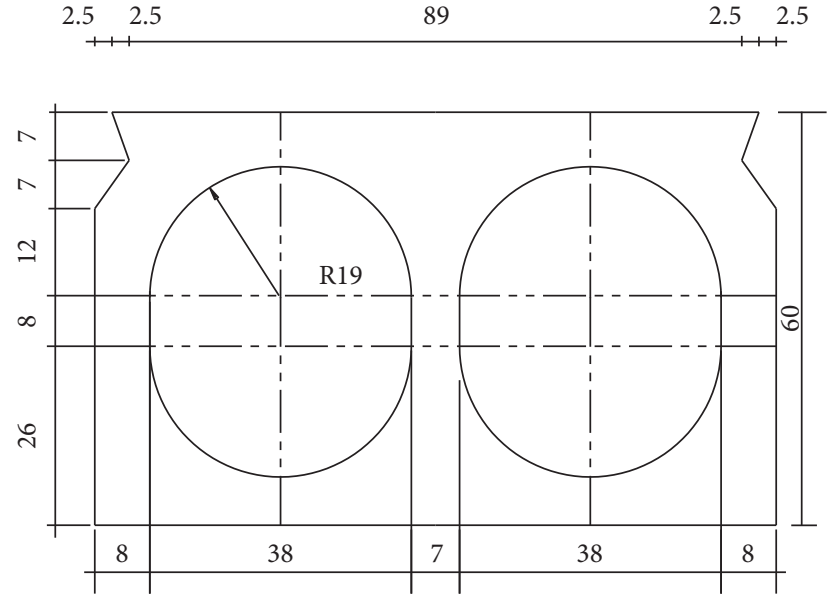

(a)

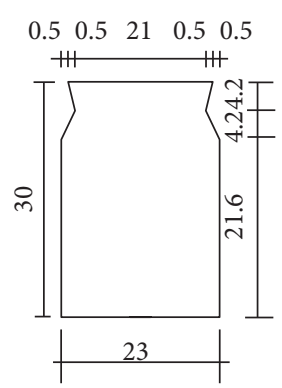

(b)

Figure 2: Cross sections of the adjacent beams: (a) the prototype; (b) test model (unit: $\mathrm{cm}$ ).

inspection accessibility increases the risk of not discovering severe damages in time.

Loading at the midspan on the edge beam was found to be the most critical, and two loading cases at this location were studied to evaluate the change of the lateral load distribution among the beams of the model bridge that consisted of eight identical beams.

2.1. Loading Case 1. The load was limited in the elastic range, and the load distribution among beams with various shear key crack lengths was investigated. A concentrated load was applied at the midspan of the edge beam (\#1) with different crack lengths of the edge shear key (\#1, i.e., between beams 1 and 2), as shown in Figure 3. The corresponding lateral load distribution factors (LLDFs) of beam \#1 of the bridge were calculated and are illustrated in Figure 4. The LLDF was calculated using the deflection of the beams because the load is proportional to the deflection if it is in the elastic range and the beams are identical. The results show that beam \#1 received $29 \%$ of the total load with a joint crack length of $0.1 L$ ( $L$ is the span length of the beam); the load share increased to $87 \%$ when the crack length reached $0.8 \mathrm{~L}$. This finding reveals that the cracking of the edge shear key significantly changes the lateral load distribution among beams and thus changes the system behavior of the bridge.

2.2. Loading Case 2. A stepwise concentrated load was applied at the middle span of beam \#1. The load was increased until beam \#1 yielded (when the loading cell unloaded automatically as triggered by a sudden increase of deflection, hereinafter referred to as load case 2-1). Beam \#1 was again loaded until the bridge failed with large deflection (referred to as load case 2-2). The deflection distribution factor of beam \#1 in loading case 2 was calculated and is shown in Figure 5. Note that the deflection gages were set to zero before each loading case.

Because load is not proportional to deflection beyond the elastic range, LLDF becomes unstable and the deflection

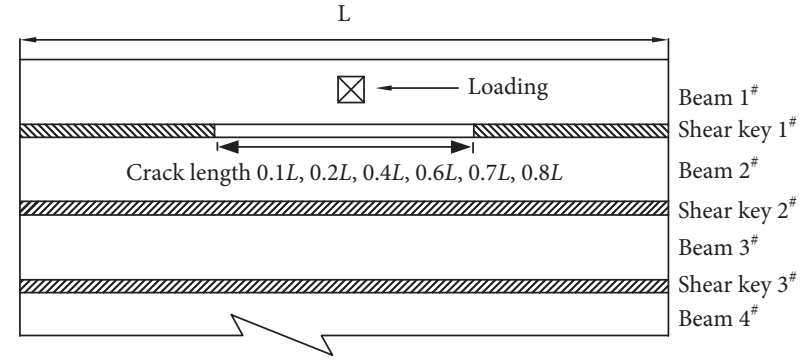

FIgURE 3: Loading scheme of the model bridge with edge shear key (\#1) cracks.

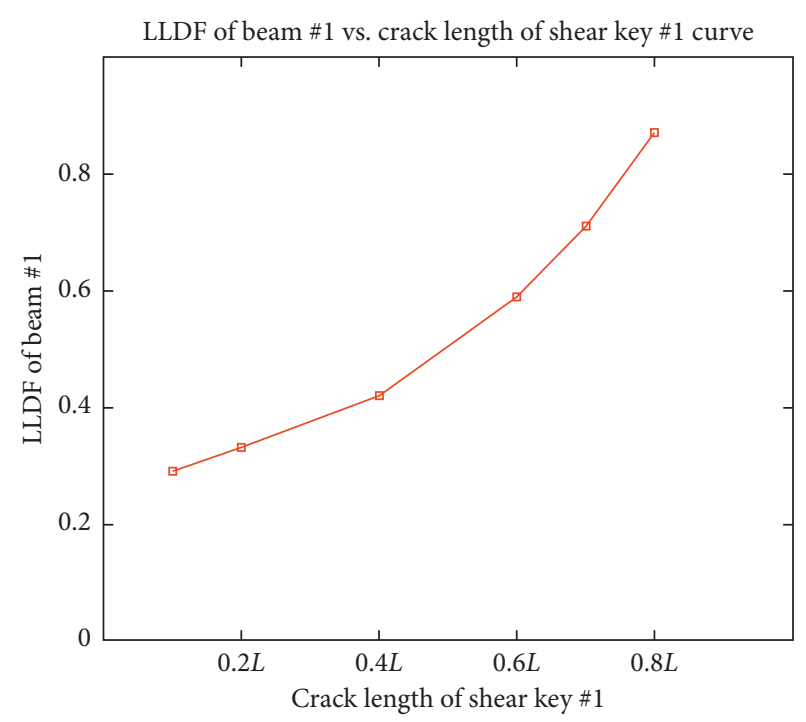

FIgURE 4: The LLDF of beam \#1 corresponding to different crack lengths of shear key \#1.

distribution factor is used instead of LLDF for the system behavior analysis of the bridge. The deflection distribution factor (DDF) of the $i^{\text {th }}$ beam is calculated according to the following equation: 


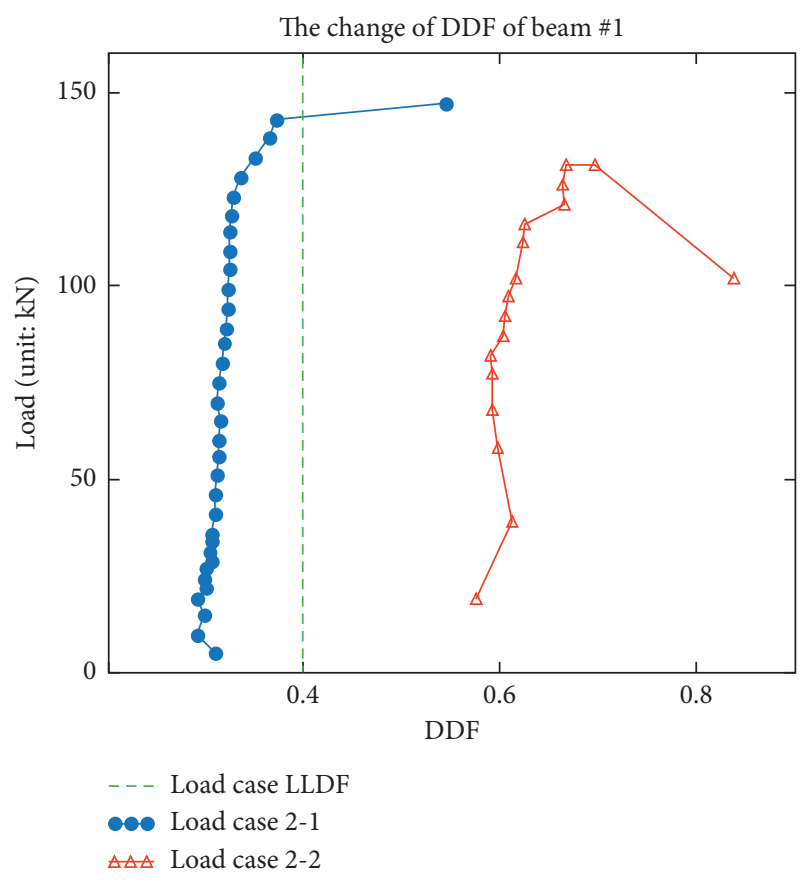

FIGURE 5: Change of the deflection distribution factor of beam \#1 with load.

$$
\mathrm{DDF}_{i}=\frac{\omega_{i}}{\sum_{1}^{n} \omega_{i}}
$$

where $\omega_{i}=$ deflection of the $i^{\text {th }}$ beam under a vertical load obtained through a load test or simulation.

The change of DDF among beams is closely related to the redundancy of adjacent precast concrete box-beam bridges. As shown in Figure 5, beam \#1 was first in the linear range with a DDF of about 0.30 in load case $2-1$. The DDF increased slowly to about 0.37 when the load on beam \#1 reached $143 \mathrm{kN}$ and then jumped to 0.54 when the edge shear key severely cracked and beam \#1 yielded. When the beam was reloaded in load case $2-2$, the DDF of beam \#1 was about 0.57 . It soon increased to and stayed at about 0.6 until the load reached $92 \mathrm{kN}$, increased to 0.7 at $131 \mathrm{kN}$, then increased quickly to 0.84 when the beam collapsed, and then the load dropped to $102 \mathrm{kN}$. A linear response was observed over the major portion of the load range. The change of DDF also reflects the condition deterioration of the shear keys. The design LLDF of beam \#1 is 0.40 (displayed as the reference line in Figure 5). The DDF (equal to LLDF in the elastic range) of beam \#1 was under 0.4 before shear key \#1 lost its function, which verifies that the design LLDF of 0.4 is reasonable. When evaluating bridges in service, however, the change of DDF must be considered according to the condition of the shear keys.

\section{Parameter Sensitivity Study on the Ultimate Loading Capacity of Adjacent Precast Concrete Box-Beam Bridges}

A parameter sensitivity study was conducted to identify which structural parameters have significant effects on the loading capacity of the adjacent precast concrete beam model bridge. As observed in the field investigation and laboratory tests, the failure mode of the shear keys is the delamination and slip at the interaction surfaces of adjoining shear keys and beams [5]. Delamination cracking is an outof-plane damage model (normally involving both opening and sliding delamination crack displacement), and the evolution is indicated by the interlaminar stresses. The shear bond strength at the interface between the beam concrete and shear key concrete highly depends on the roughness of the contact interface, the bonding material applied, and the contour of the contact surface. Thus, a surface-based cohesive behavior is employed in this study. And the cohesive strength, cohesive stiffness, and plastic displacement of shear keys were considered selected in the sensitivity study. In addition, the yield strength of main reinforcement and the total area of main reinforcement usually dominate the load capacity of concrete beams. For the above consideration, the following five independent variables were considered in the sensitivity study: the cohesive strength of shear keys $\left(C_{s}\right)$, the cohesive stiffness $(K)$ of shear keys, the plastic displacement $\left(d_{\mathrm{p}}\right)$ of shear keys, the yield strength of main reinforcement $\left(f_{y}\right)$, and the total area of main reinforcement bars $\left(A_{s}\right)$.

The statistical parameters of variables $C_{s}, K$, and $d_{\mathrm{p}}$ were considered to follow a normal distribution, and the coefficient of variance (COV) was taken as 0.15 according to previous studies, comparable to the COV used for the variables for load distribution because all the three variables contribute to the load distribution of the beams [12]. When no reinforcement crossing the interface is provided, the cohesive strength of shear key, $C_{s}$, is approximatively equal to the product of the design strength of the shear key concrete and design coefficient of cohesion, where in the absence of detailed information and for nonuniform interface surfaces, design coefficient of cohesion is 0.5 [13]. The design tensile strength of the shear key concrete (C20) is $1.54 \mathrm{MPa}$. Thus, $\mathrm{C}_{\mathrm{s}}=0.77 \mathrm{MPa}$. The cohesive stiffness of shear key, $K$, was estimated by dividing the maximum cohesive stress by corresponding separation, which was obtained in the laboratory load tests. $d_{\mathrm{p}}$ is the depth of shear key concrete. The statistical parameters of $f_{y}$ and $A_{\mathrm{s}}$ were taken from the values recommended by Chinese bridge design standards [14]. The statistical parameters are summarized in Table 1.

The marginal effect of each variable on the loading capacity of the bridge was investigated using a 3D nonlinear finite element analysis with the Abaqus/CAE 6.14 software package, which was calibrated using the experiment results of the model bridge. A concrete damaged plasticity (CPD) model was employed to define the plastic properties of concrete. The stress-strain curve of the reinforcement bar was assumed to be perfectly elastic-plastic. The loading capacity of the bridge was determined when the tensile strain of the reinforcement reached 0.002 . A total of 9 points were considered for each variable, including $\mu, \mu \pm \sigma$, $\mu \pm 1.5 \sigma, \mu \pm 2 \sigma$, and $\mu \pm 3 \sigma$, where $\mu$ and $\sigma$ are the mean value and standard deviation of the variable, respectively. All other variables were held constant when one variable was evaluated. The marginal effect of the variables is graphed in Figure 6. It is shown that in the range of three sigma, the 
TABLE 1: Statistical parameters of each variable.

\begin{tabular}{lccc}
\hline Variable & Distribution type & Mean value, $\mu$ & COV \\
\hline$C_{\mathrm{s}}$ & Normal & $0.77 \mathrm{MPa}$ & 0.15 \\
$K$ & Normal & $3 \mathrm{MPa} / \mathrm{mm}$ & 0.15 \\
$d_{\mathrm{p}}$ & Normal & $0.0008 \mathrm{~m}$ & 0.15 \\
$A_{\mathrm{s}}$ & Normal & $201.1 \mathrm{~mm}^{2}$ & 0.035 \\
$f_{y}$ & Normal & $380 \mathrm{MPa}$ & 0.068 \\
\hline
\end{tabular}

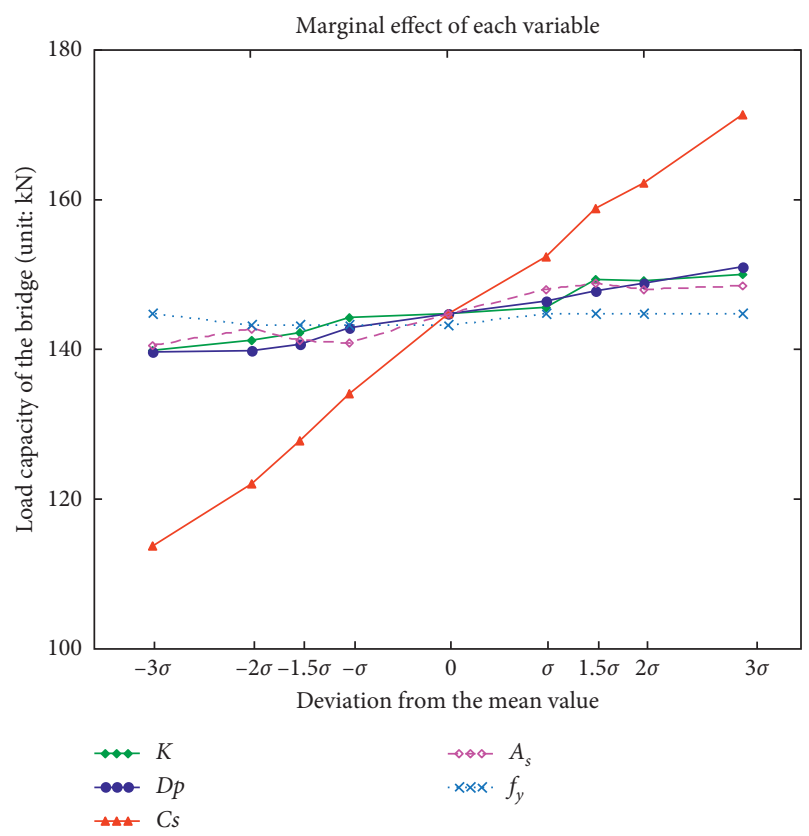

FIgURE 6: Marginal effect of the variables on the load-carrying capacity of the bridge.

slope coefficients (equivalent to the overall marginal effects) of $C_{\mathrm{s}}, d_{\mathrm{p}}$, and $K_{\mathrm{c}}$ were slightly greater than the other two. Thus, the sensitivity follows the order $C_{s}>d_{\mathrm{p}}>K_{\mathrm{c}}>A_{\mathrm{s}}>f_{y}$. The three most sensitive parameters on the loading capacity of the bridge are all associated with the properties of the shear keys. This verifies the observation that cracking and deterioration of shear keys significantly affect the system capacity of the bridge. Compared to the property change of shear keys, the residual strength (embodied in $A_{s}$ and $f_{y}$ ) of the beam has less influence on the loading capacity of the bridge. Besides, the failure of a shear key (shear failure) is brittle. Based on the above analysis, it is concluded that the nonlinear behavior is less significant for the redundancy assessment for adjacent precast concrete box-beam bridges, which agrees with the test results shown in Figure 5.

\section{Proposed System Performance Evaluation Method}

The load-carrying capacity of an adjacent precast concrete box-beam bridge is presently evaluated by calculating the ultimate section capacity of an individual beam and the load distribution factors among the beams of the bridge. The system capacity of a bridge is evaluated according to redundancy at two levels: the system and component level, as demonstrated in Figure 7. The load redistribution capacity among beams is considered the system-level redundancy. The reserve strength over the design capacity of a component is considered the component-level redundancy, which permits local yielding and redistribution of component internal forces (especially in most heavily loaded members). Studying both the system-level and component-level redundancy provides a full understanding of the system mechanism in a multibeam bridge system.

The redundancy factors are calculated as

$$
\begin{aligned}
\mathrm{RF} & =\mathrm{RF}_{\text {comp }} \times \mathrm{RF}_{\text {sys }}, \\
\mathrm{RF}_{\text {comp }} & =\frac{R_{\text {real }}}{R_{\text {design }}}, \\
\mathrm{RF}_{\text {sys }} & =\frac{\mathrm{LLDF}_{\text {design }}}{\mathrm{DDF}_{\text {real }}},
\end{aligned}
$$

where $R_{\text {real }}$ is the actual resistance of an individual beam obtained from simulation or load testing, $R_{\text {design }}$ is the unfactored design resistance of the beam, $\mathrm{DDF}_{\text {real }}$ is the measured DDF, which can be obtained by linear simulation or diagnostic load test, and $\mathrm{LLDF}_{\text {design }}$ is determined according to bridge codes, which is equal to the design DDF in the elastic range.

For concrete beams, $\mathrm{RF}_{\text {comp }}$ is normally higher than 1.0 and can be neglected. The system-level redundancy can be evaluated by the ratio of the design LLDF (or DDF) to measured DDF. The LLDF and DDF are equal for bridges in service, which are generally in the elastic range. The design load distribution factor can be calculated with the method provided in a design code or through a linear analysis. The measured DDF is computed using equation (1), and the data used in equation (1) can be obtained through a field load testing or an FE simulation. The approach is demonstrated in the following case study.

\section{Case Study}

Beida Bridge was built in 1999 that crosses the Tuman river in Kashi city, Xinjiang Uygur Autonomous Region, China. The bridge has three simply supported prestressed concrete spans, as shown in Figure 8. For each half of the bridge, six adjacent precast prestressed concrete box beams are used for the sidewalk and bike lane and nine adjacent precast prestressed concrete box beams are used for the driving lane. No as-built drawings were available; thus, efforts were made to determine the geometric information of the bridge. Dimensions of the bridge were measured in the field, and the drawings of bridges of the same structural type on the same route or nearby were checked. It was decided that the standard drawing JT/GQB001-91 was the right one for this bridge. Noted that this bridge used shallow shear keys without any transverse post-tensioning, and concrete pavement on the top was not composite with the beams, 


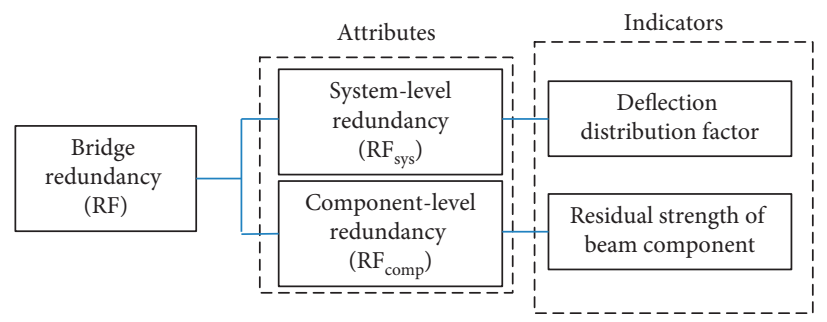

FIGURE 7: Structural redundancy of a multibeam bridge.

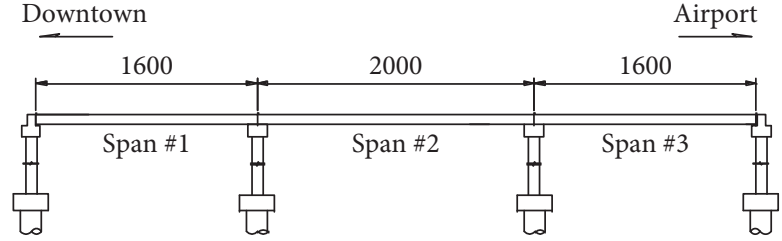

(a)

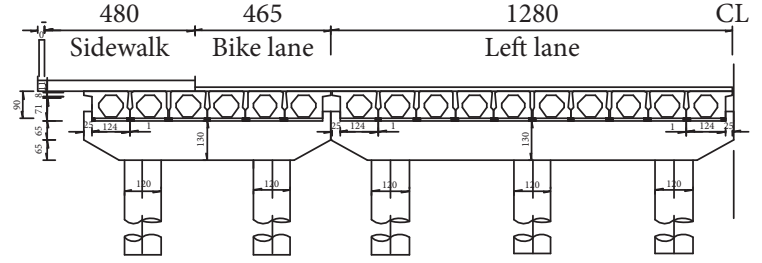

(b)

Figure 8: Schematic of Beida Bridge (unit: $\mathrm{cm}$ ). (a) Elevation. (b) Half cross section (left) of the bridge.

which was the prevalent precast adjacent box beam bridges built in or before the 1990s in China.

Field inspection and material examinations were conducted on the bridge. The field inspection revealed that the shear keys of the bridge were in a severe condition, especially on span \#3, as shown in Figure 9.

Diagnostic loading tests were conducted on the left lanes of spans \#2 and \#3, respectively. Since the left lanes of span \#3 were in a worse condition, it was the focus of this research. Two load cases were tested: in load case I, the bridge was subjected to a symmetrical loading, and in load case II, the bridge was subjected to an asymmetrical loading. The loading layout is shown in Figure 10. Trucks were moved one meter towards beam \#10 (B10 in Figure 10) in load case II based on the basis of load case I. Each load case consisted of four loading steps or subload cases, as summarized in Table 2. For example, LC I-1 denotes placing truck SYC1 at the designated position in the symmetrical load case; LC II-3 denotes placing 3 trucks, SYC1, SYC2, and SYC3, at the designated positions in the asymmetrical load case.

A grillage model was constructed following the approach proposed by Hambly [15] using the structural analysis program Midas Civil 2016, where the bridge system was discretized as longitudinal and transverse beam elements, as shown in Figure 11. Beam elements were used for the box beams, and pavement on the top of the beams were simulated as plates attached to the same nodes as beam elements, but with different offsets. The shear keys (hinge joints) were simulated as virtual transverse beams. A total of 10 longitudinal grillage beams were placed along the centerline of each beam. 16 virtual beams were used to simulate each shear key, and the length of each virtual beam was $L / 16$ ( $L$ denotes the length of the shear key). The properties of the virtual transverse beams that were deemed to transfer loads between longitudinal beams were determined based on the shear capacity of the shear keys. For instance, the cross

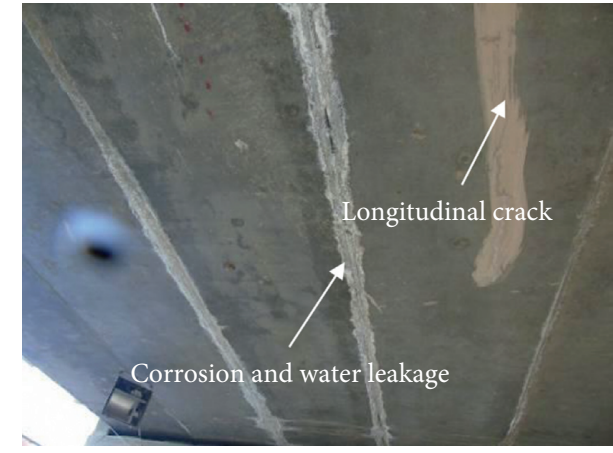

Figure 9: Water leakage and corrosion of the shear keys in span \#3.

section of the virtual beam was $0.125 \mathrm{~m}$ (width) $\times 0.05 \mathrm{~m}$ (depth). The length and location of the virtual beam were adjusted in response to the cracking of the shear key. For instance, if a crack length of $L / 16$ was assumed at the midspan, the corresponding portion of the virtual beam would be deleted in the finite element model. The failure of the bridge was defined in terms of the load that leads to the formation of a plastic mechanism in one longitudinal beam. The plastic hinge depth was assumed to be $1 / 2$ of the depth of the cross section [9]. The maximum plastic hinge rotation determines the critical point at which the prestressed beam fails. For the bridge members, the critical plastic hinge rotation was equal to $0.0402 \mathrm{rad}$ [8]. The convergence criterion was that the tensile strain of rebar reaches 0.002 .

The simulation results agree well with the actual deflection obtained from the diagnostic load test, as shown in Figure 12. Load case II-2 was used in the calculation where two trucks were placed side-by-side at the designated positions, which causes the biggest deflection differences between beams and is the most critical load configuration. The load transverse distribution factor of the exterior beam in 


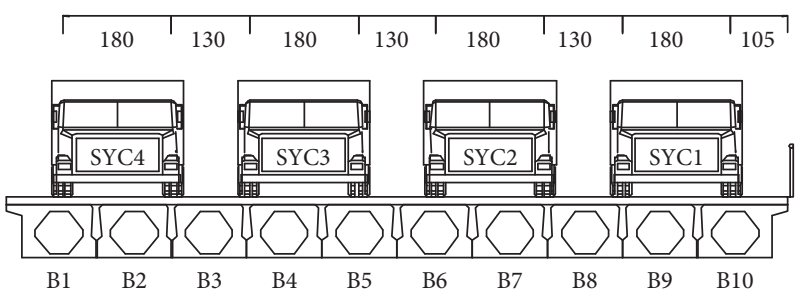

(a)

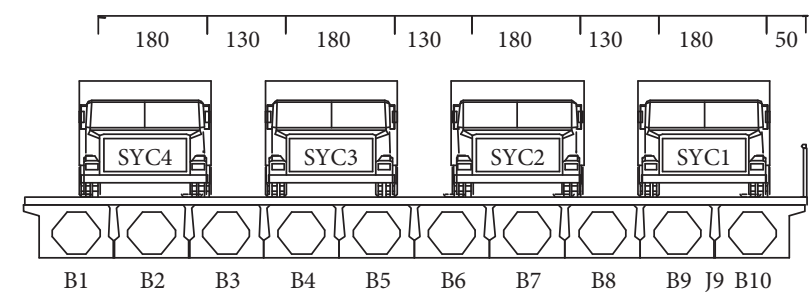

(b)

FIgURE 10: Loading layout (unit: $\mathrm{cm}$ ). (a) Load case I: symmetrical loading. (b) Load case II: asymmetrical loading.

TABLE 2: Loading cases.

\begin{tabular}{lccc}
\hline Load case & Truck(s) in position (a) & Load case & Truck(s) in position (b) \\
\hline LC I-1 & SYC1 & LC II-1 & SYC1 \\
LC I-2 & SYC1 + SYC2 & LC II-2 & SYC1 + SYC2 \\
LC I-3 & SYC1 + SYC2 + SYC3 & LC II-3 & SYC1 + SYC2 + SYC3 \\
LC I-4 & SYC1 + SYC2 + SYC3 + SYC4 & LC II-4 & SYC1 + SYC2 + SYC3 +SYC4 \\
\hline
\end{tabular}



Figure 11: Midas Civil grillage model of Beida bridge.

load case II-2 (beam B10) is 0.34, which was used as a reference for assessing the crack length of the exterior shear key that is between beams \#9 and \#10 (B9 and B10 in Figure 11).

$\mathrm{V}$-20 trucks were used that is a single unit truck with one $60 \mathrm{kN}$ front axle and two $120 \mathrm{kN}$ back axles, as shown in Figure 13.

According to the bridge loading capacity evaluation code [7], the loading capacity of the bridge in terms of the number of V-20 truck pairs (load factor 1) in load case II-2 that would lead to the first beam failure is [8]

$$
\mathrm{LF}_{1}=\frac{R-D}{\mathrm{DF}_{1} \times \mathrm{LL}_{V-20}},
$$

where $R$ is the beam's unfactored moment capacity, $D$ is the beam's unfactored dead load moment, $\mathrm{DF}_{1}$ is the elastic lateral distribution load factor of the beam, and $\mathrm{LL}_{V-20}$ is the total live load moment effect caused by the two V-20 vehicles. Since the cracking of shear key would considerably affect the lateral distribution of the vehicle load among the beams, the load share $\mathrm{DF}_{1} \mathrm{LL}_{V-20}\left(\right.$ or $\left.\mathrm{LF}_{1}\right)$ can reflect the condition deterioration of the shear key. Thus, the approximate crack length of the shear key can be deduced if the corresponding $\mathrm{LF}_{1}$ for specified crack lengths (e.g. tenth points) was available; this methodology was employed in this study to estimate the cracking length of the exterior shear key of Beida bridge.

For better accuracy, the load share of the beam $\mathrm{DF}_{1} \mathrm{LL}_{V-20}$ was obtained from a Midas Civil simulation, rather than using a theoretical load share obtained using a distribution factor. Note that the load and resistance factors were ignored in equation (8) because the intention is to evaluate the load-carrying capacity rather than to provide safety envelops for design and load rating purposes.

The moment capacity of the exterior beam, denoted by $R$, is equal to $3891 \mathrm{kN}-\mathrm{m}$ calculated from the beam cross section configuration. The dead load moment at the midspan of the exterior beam is $D=605.4 \mathrm{kN}-\mathrm{m}$ from a linear elastic analysis. The share of the moment by the exterior beam from the two side-by-side design trucks is $362.9 \mathrm{kN}-\mathrm{m}$, which is $\mathrm{DF}_{1} \mathrm{LL}_{V-20}$ in equation (5). The load factor that leads to first member failure in bending $\left(\mathrm{LF}_{1}\right)$ is 9.1 , as calculated using equation (8), assuming the bridge is in a good condition and the traditional linear elastic analysis method applies. This result reveals that if one is to follow the traditional bridge analysis method, the first member of the bridge will reach its ultimate capacity at a load equal to 9.1 times the effect of two $\mathrm{V}-20$ trucks placed at the designated locations in load case II-2.

The system performance of the bridge in terms of redundancy was first evaluated using an existing recognized method [8]. A nonlinear pushdown analysis was performed on the bridge assuming that the bridge will behave nonlinearly after damages occur. The analysis was applied with load case II-2 for the intact condition and for different crack lengths of the edge shear key (hinge joint J9). $\mathrm{LF}_{u}$ is designated as the ultimate load capacity of the bridge in terms of the number of V-20 truck pairs in the designated location. According to the nonlinear pushdown analysis, $\mathrm{LF}_{u} \approx 10$ when the bridge is intact, $\mathrm{LF}_{u} \approx 9$ when the crack length of the edge shear key is in the range of $L / 16$ to $9 L / 16$, and $\mathrm{LF}_{u} \approx 8$ when the crack length of the shear key exceeds $11 L / 16$. 


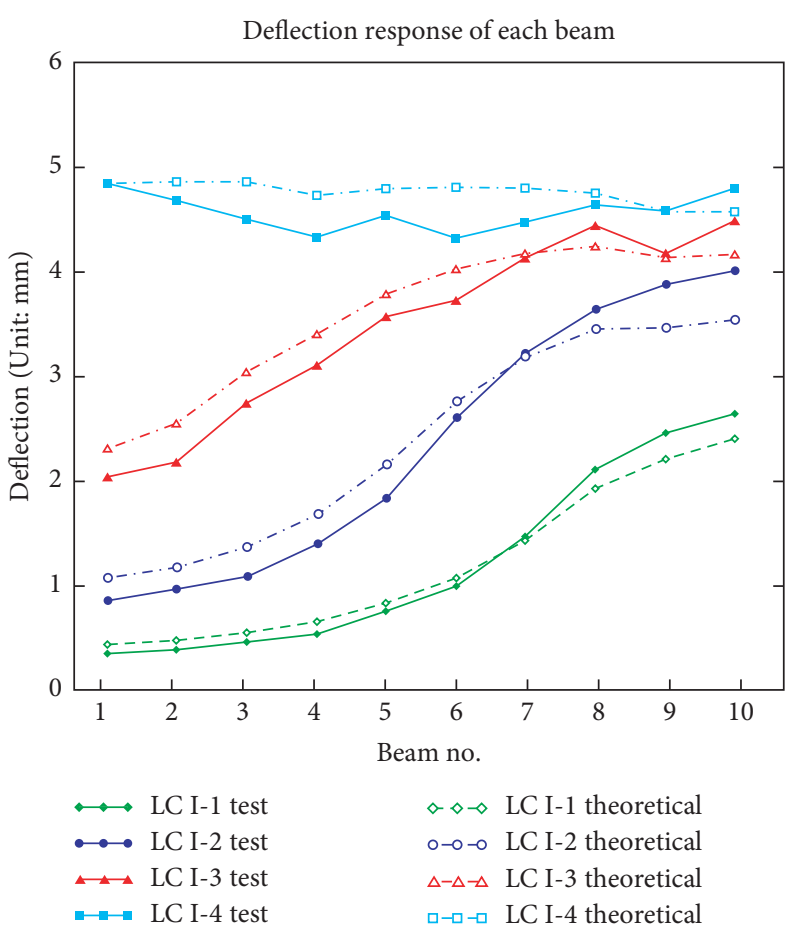

(a)

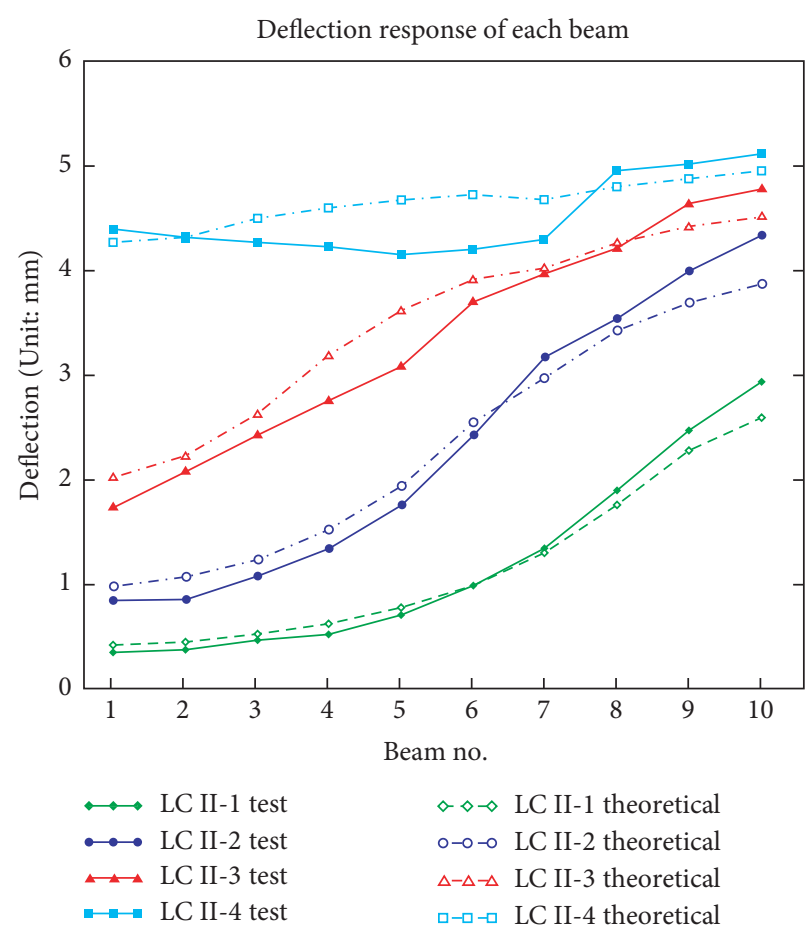

(b)

FIGURE 12: Vertical displacement response of beams for each load case. (a) Load case I: symmetrical loading. (b) Load case II: asymmetrical loading.
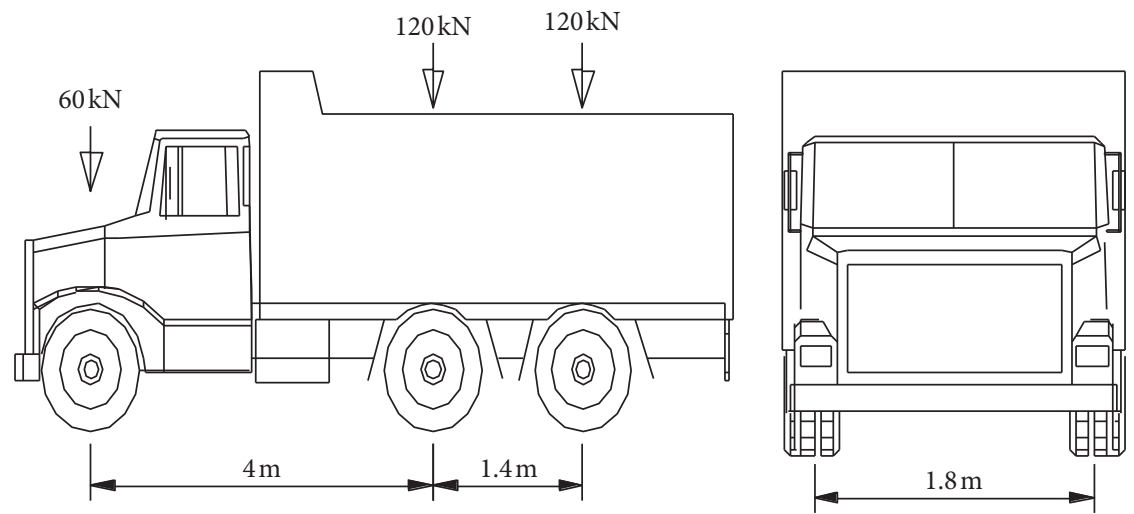

FIGURE 13: V-20 truck load.

The system resistance reserve ratio, $R_{u}$, of the bridge with different exterior shear key crack lengths was computed by using the data obtained through simulation and is summarized in Table 3. As an example, $\mathrm{LF}_{u}=9.01$ when the crack length is $9 L / 16$, and $R_{u}=\mathrm{LF}_{u} / \mathrm{LF}_{1}=9.01 / 9.1=0.99$ according to Ghosn's approach.

The design load distribution factor for the exterior beam is $1 / 2(0.099+0.145+0.192+0.259)=0.3475$, according to the design code method, as shown in Figure 14. The field LLDF based on the deflection measurement is 0.345 . Because the simulation results show that the LLDF of the exterior beam is 0.345 when the crack length of the exterior shear key is about $9 L / 16$, the crack length of the exterior shear key was estimated as $9 L / 16$.
TABLE 3: System reserve ratio, $R_{u}$, of the superstructure with different crack lengths of the shear key $\# 9$.

\begin{tabular}{lcc}
\hline $\begin{array}{l}\text { Crack length of } \\
\text { shear key } \# 9\end{array}$ & $\begin{array}{c}\text { Ghosn's } \\
\text { approach }\end{array}$ & $\begin{array}{c}\text { Proposed } \\
\text { approach }\end{array}$ \\
\hline 0 (intact) & 1.10 & 1.04 \\
$1 L / 16$ & 1.01 & 1.04 \\
$3 L / 16$ & 1.01 & 1.03 \\
$5 L / 16$ & 1.00 & 1.02 \\
$7 L / 16$ & 1.00 & 1.01 \\
$9 L / 16$ & 0.99 & 1.01 \\
$11 L / 16$ & 0.90 & 0.93 \\
$13 L / 16$ & 0.87 & 0.87 \\
$15 L / 16$ & 0.79 & 0.81 \\
\hline
\end{tabular}




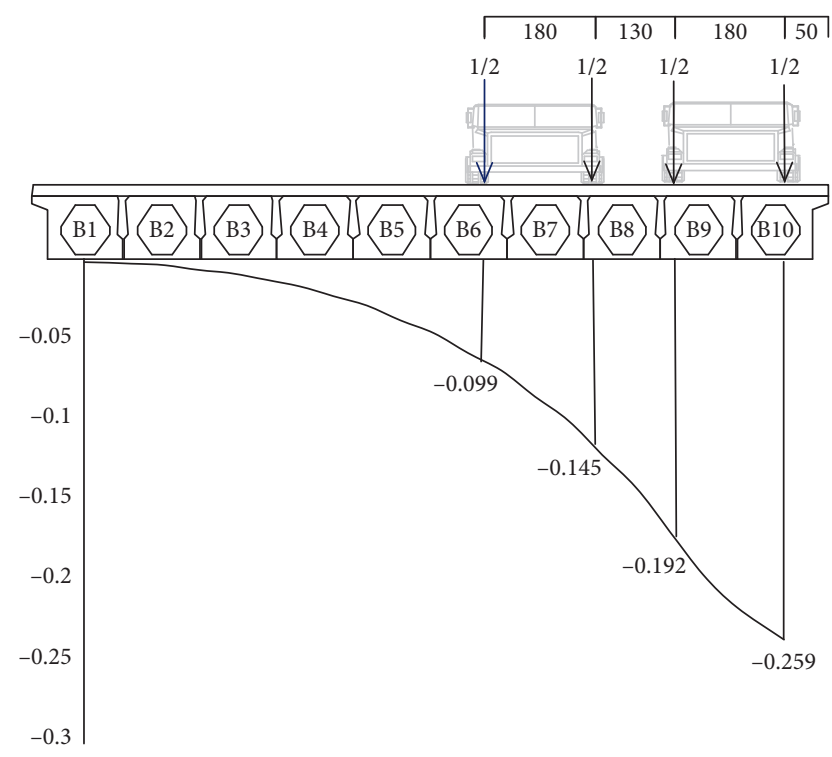

Figure 14: The influence line of beam \#10 and the layout for computing the LLDF of beam \#10 with two trucks at critical positions.

The system reserve factor was then calculated according to the method proposed in this research. For instance, the deflection distribution factor for the exterior beam is 0.345 based on the field deflection measurement when the crack length is $9 L / 16$; thus, the system-level redundancy $\mathrm{RF}_{\text {sys }}=$ $0.3475 / 0.345=1.01$ according to equation (4). According to the field inspection, the beam was observed in good condition, as shown in Figure 9; the longitudinal cracks were basically in the shear keys between the beams. Therefore, the beam was considered having sufficient strength reserve and the component-level redundancy factor can be conservatively assumed as 1.0, that is, $\mathrm{RF}_{\text {comp }}=1.0$. Consequently, the system reserve ratio $R=\mathrm{RF}_{\text {sys }}=1.01$ according to equation (5).

The system reserve ratios for various joint crack lengths were calculated using the two approaches and are compared in Table 3. It is found that the two approaches agree well with each other. However, the proposed approach can greatly reduce the computation complexity. Also, as mentioned before, the crack length of the edge shear key (J9) of this bridge is $9 L / 16$, and the system reserve ratio is about 0.99 based on Ghosn's approach and 1.01 based on the proposed method. The recommended minimum system reserve ratios for system ultimate limit state and functionality limit state are 1.30 and 1.10, respectively, according to NCHRP reports 406 and 776 . Thus, the redundancy of this bridge is not satisfactory.

\section{Summary and Conclusion}

A new approach is developed in this research based on a linear finite element analysis and the field deflection measurement to evaluate the system performance of adjacent precast concrete box-beam bridges. The results obtained using the approach agree well with those from a recognized method in the case study. The proposed approach can reduce the computation complexity and is suitable for the practitioners to use. Another advantage of the proposed method over the existing method is that it can be verified through field load testing. The analysis revealed that the level of redundancy of the bridge in the case study does not meet the recommended standard, indicating that the system factor recommended by the bridge evaluation code for this bridge is not appropriate. Further research on the redundancy level of this type of bridges is recommended.

\section{Data Availability}

The data used to support the findings of this study are available upon request. Dr. Leng should be contacted to request the data; she can be reached at yllengnmsu@gmail.com.

\section{Conflicts of Interest}

The authors declare that they have no conflicts of interest.

\section{References}

[1] C. L. Hulsbos, "Lateral distribution of load in multibeam bridges," Highway Research Board Bulletin 339 Transportation Research Board, Washington, DC, USA, 1962.

[2] H. G. Russell, "Adjacent precast concrete box beam bridges: connection details," NCHRP Report Synthesis 393, Transportation Research Board, Washington, DC, USA, 2009.

[3] Y. Leng, J. Zhang, R. Jiang, and H. He, "Experimental research on transverse load distribution of prefabricated hollow slab concrete bridges with shear key cracks," IABSE Symposium Report vol. 99, International Association for Bridge and Structural Engineering, Zürich, Switzerland, 2013.

[4] Y. Leng, J. Zhang, R. Jiang, H. He, and J. Zhou, "Experimental research on strengthening transverse connections of prefabricated concrete hollow core slab beam bridges," in Proceedings of Transportation Research Board 94th Annual Meeting, Washington DC, January 2015.

[5] Y. Leng, "System safety and reliability assessment for adjacent precast concrete box beam bridges," Doctorate dissertation New Mexico State University, Las Cruces, NM, USA, 2017.

[6] AASHTO, AASHTO LRFD Bridge Design Specifications, AASHTO, Washington, DC, USA, 7th edition, 2017.

[7] AASHTO, AASHTO Manual for Bridge Evaluation, AASHTO, Washington, DC, USA, 3rd edition, 2018.

[8] M. Ghosn and F. Moses, "Redundancy in highway bridge superstructures," NCHRP Report No. 406, Transportation Research Board, Washington, DC, USA, 1998.

[9] M. Ghosn and J. Yang, Bridge System Safety and Redundancy, NCHRP Report No. 776, Washington, DC, USA, 2014.

[10] S. G. Pinjarkar, "An overview of current worldwide practices for nondestructive load testing for bridge rating and evaluation," in Proceedings of the 5th Annual International Bridge Conference, Pittsburgh, PA, USA, 1988.

[11] GB/J50283-1999, Unified Standard for Reliability Design of Highway Engineering Structures, China Plan Press, Beijing, China, 1999, in Chinese.

[12] F. Moses and V. Dhirendra, "Load Capacity Evaluation of Existing bridges," NCHRP Report No. 301, Transportation Research Board, Washington, DC, USA, 1987. 
[13] M. Pedro and N. Eduardo, "Assessment of the Shear Strength between Concrete layers," in Proceedings of the 8th Fib Ph.D. Symposium in KGS, Lyngby, Denmark, June 2010.

[14] GB50010-2010, Code for Design of Concrete Structures, China Plan Press, Beijing, China, 2010, in Chinese.

[15] E. C. Hambly, Bridge Deck Behaviour, CRC Press, New York, NY, USA, 1991. 